\title{
The interplay of psychosis and victimisation across the life course: a prospective study in the general population
}

\author{
Steven Honings ${ }^{1} \cdot$ Marjan Drukker $^{1} \cdot$ Margreet ten Have $^{2} \cdot$ Ron de Graaf $^{2}$. \\ Saskia van Dorsselaer ${ }^{2} \cdot \mathrm{Jim}_{\text {van }} \mathrm{Os}^{1,3,4}$
}

Received: 29 March 2017 / Accepted: 7 August 2017/Published online: 31 August 2017

(c) The Author(s) 2017. This article is an open access publication

\begin{abstract}
Purpose Psychosis has been associated with adult victimisation. However, it remains unclear whether psychosis predicts incident adult victimisation, or whether adult victimisation predicts incident psychosis. Furthermore, a moderating effect of childhood victimisation on the association between psychosis and adult victimisation has not been investigated.

Methods The longitudinal association between baseline psychotic experiences and six-year incidence of adult victimisation was assessed in a prospective general population cohort of 6646 adults using logistic regression analysis. The association between baseline adult victimisation and six-year incidence of psychotic experiences was examined as well. Furthermore, the moderating effect of childhood victimisation on these bidirectional associations was analysed.

Results Psychotic experiences and childhood victimisation were both associated with an increased risk of incident adult victimisation. However, this was through competing pathways, as suggested by a negative interaction between
\end{abstract}

Jim van Os

vanosj@gmail.com

1 Department of Psychiatry and Psychology, South Limburg Mental Health Research and Teaching Network, Maastricht University Medical Centre, Maastricht, The Netherlands

2 Netherlands Institute of Mental Health and Addiction, Utrecht, The Netherlands

3 King's Health Partners, Department of Psychosis Studies, Institute of Psychiatry, King's College London, London, UK

4 Department of Psychiatry, Brain Center Rudolf Magnus Institute, University Medical Center Utrecht, PO BOX 85500, 3508 GA Utrecht, The Netherlands psychotic experiences and childhood victimisation. Baseline adult victimisation and childhood victimisation both independently increased the risk of incident psychotic experiences, but there was no interaction between adult victimisation and childhood victimisation.

Conclusions Psychosis and victimisation are interconnected throughout the life course. Childhood victimisation is connected to psychosis through two pathways: one direct and one indirect through adult victimisation. In individuals without childhood victimisation, psychosis and adult victimisation bidirectionally impact on each other.

Keywords Psychosis - Psychotic experience · Violence . Childhood trauma $\cdot$ Victimisation

\section{Introduction}

Psychosis has been associated with an increased risk of violence perpetration [1-5]. However, contrary to the common stereotype that individuals with severe mental illness are dangerous [6], evidence shows that these individuals are more likely to be victims of violence than perpetrators of violence [7, 8]. Among individuals with psychosis, victimisation is prevalent [9], both during childhood [10-12] and adulthood [13-15].

Various forms of childhood victimisation, including sexual abuse, physical abuse, emotional abuse [16] and being bullied [17], have been associated with psychosis in the literature [10-12]. Childhood victimisation has been associated with both psychotic experiences (PE) [10] and full-blown psychotic disorder [11, 12], thus covering the complete spectrum of the extended psychosis phenotype [18-20]. Most research to date has focussed on the hypothesis that childhood victimisation is a risk factor for 
the development of psychosis [16]. However, evidence shows that PE increase the risk of incident childhood victimisation as well, thereby showing that the association between childhood victimisation and PE is bidirectional [10].

Recently, studies found evidence that psychosis is associated with adult victimisation as well. Compared with general population individuals, the prevalence of criminal and violent victimisation among individuals with psychosis and other severe mental illnesses was high [13-15]. However, the nature of this association remains unclear, since most studies to date had some methodological limitations. First, most studies to date used cross-sectional study designs to examine the association between psychosis and adult victimisation [13-15]. Therefore, it is unclear whether psychosis increases the risk of incident adult victimisation or vice versa. To our knowledge, only one longitudinal study examined the association between adult victimisation and psychosis, showing that adult adversities were associated with an increased risk of incident PE [21]. However, no longitudinal study to date examined whether psychosis predicts incident adult victimisation. Thus, it remains unknown whether the association between psychosis and adult victimisation is bidirectional, similar to the association between psychosis and childhood victimisation [10]. Second, few studies examined the influence of childhood victimisation on the association between psychosis and adult victimisation [22], while childhood victimisation is associated with an increased risk of both psychosis [10-12] and adult victimisation [23-29]. Previous studies have shown that childhood victimisation and various environmental factors combine synergistically to increase the risk of PE over and above their isolated products [21, 30-32]. However, no previous study examined whether psychosis predicts incident adult victimisation, while simultaneously examining the potential moderating effect of childhood victimisation.

The present study aims to bridge these gaps in the literature. In line with the research on childhood victimisation and PE, we hypothesized that there would be a bidirectional association between PE and adult victimisation, that is moderated by the presence of childhood victimisation (Fig. 1). More specifically, we hypothesized that: (1) PE are associated with incident adult victimisation; (2) childhood victimisation is associated with incident adult victimisation; (3) the co-occurrence of $\mathrm{PE}$ and childhood victimisation predicts a stronger association with incident adult victimisation than the product of their isolated effects; (4) adult victimisation is associated with incident PE; (5) childhood victimisation is associated with incident PE; (6) the co-occurrence of adult victimisation and childhood victimisation predicts a stronger association with incident PE than the product of their isolated effects.

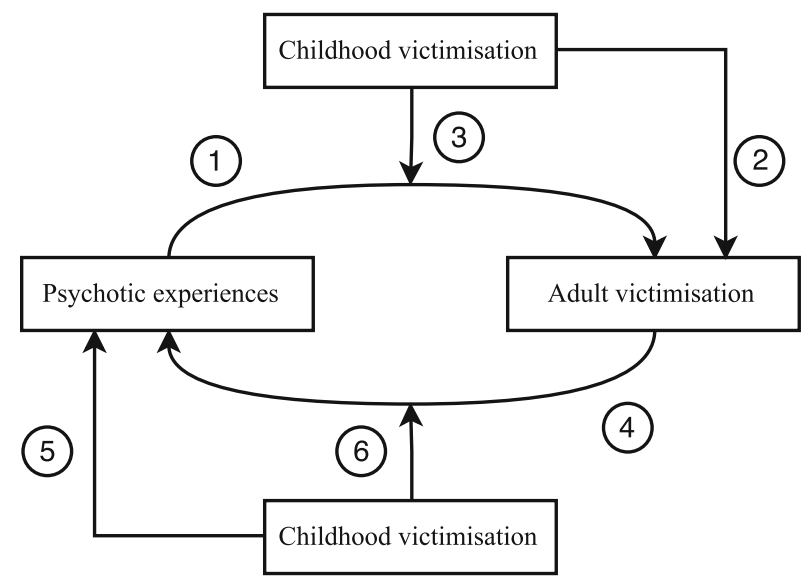

Fig. 1 Hypotheses relating to the bidirectional association between psychotic experiences and victimisation

\section{Methods}

\section{Sample}

This study uses data pertaining to the second Netherlands Mental Health Survey and Incidence Study (NEMESIS-2), a longitudinal study of the prevalence, incidence, course and consequences of mental disorders in the Dutch general population [33]. Participants were selected based on a multistage random sampling procedure. At baseline (T0), 6646 persons aged 18-64 years were interviewed with the Composite International Diagnostic Interview (CIDI) version 3.0, a fully structured lay-administered diagnostic interview generating DSM-IV diagnoses [34]. At followup, respectively, three (T1, $N=5503)$ and 6 years (T2, $N=4618)$ after baseline, subjects were re-interviewed. A more comprehensive description of the design can be found elsewhere [33]. In the present analyses, only individuals who responded to all three assessments were included.

\section{Psychotic experiences}

PE were assessed at baseline (T0) and both follow-up measurements (T1, T2) using a psychosis add-on instrument based on the sections of psychotic symptoms in CIDI versions 1.0 and 2.0. The instrument consisted of 20 questions regarding lifetime PE. The 20 items included 15 delusional experiences and 5 hallucinatory experiences, described in detail elsewhere [35]. Individuals with at least one lifetime PE were contacted for a re-interview by telephone. Re-interviews were conducted by an experienced clinician at the level of psychologist or psychiatrist, within 8 weeks after the initial interview using questions from the Structured Clinical Interview for DSM-IV. Findings from all re-interviews were discussed with a second clinician [35]. PE were defined as clinically validated when 
the psychotic nature of the self-reported PE was confirmed at clinical re-interview. The response rates for the re-interviews at the three time points were $73 \%$ (T0), $84 \%$ (T1) and $81 \%$ (T2), respectively. At baseline, lifetime PE were assessed. At both follow-up surveys, participants were asked about PE since the last interview. For the present analyses, only clinically validated PE were used. Individuals with self-reported PE who could not be reached for reinterview were excluded from the analyses. PE were defined present if the participant had at least one clinically validated PE. Incident PE was defined present if a participant reported at least one clinically validated $\mathrm{PE}$ at one of the follow-up surveys, but reported no PE at baseline.

\section{Childhood victimisation}

At baseline, childhood victimisation was assessed retrospectively. Participants were asked whether they had experienced emotional abuse, psychological abuse, physical abuse or sexual abuse before the age of 16 years. Consistent with previous analyses [7], childhood abuse was defined present if a participant had experienced psychological abuse or emotional abuse on two or more occasions, or physical abuse/sexual abuse on one or more occasion. In addition, being bullied was assessed at baseline by asking participants if they had been bullied regularly before the age of 16 years. For the present study, childhood victimisation was defined present if a participant reported childhood abuse or bullying at baseline. Individuals with missing data on childhood victimisation were excluded from the present analyses $(n=140)$.

\section{Adult victimisation}

At baseline, participants were asked about lifetime violent and psychological victimisation by an intimate partner. In addition, lifetime sexual victimisation by any person in general since the age of 16 years was assessed. To increase the likelihood of these forms of victimisation being reported, the interviewer did not mention any type of victimisation during the interview. Instead, different forms of victimisation were listed and numbered in a booklet. Participants were asked to provide the numbers of the type of victimisation. Psychological victimisation included namecalling, offending, belittling, punishing unjustly, blackmailing and threatening. Physical victimisation included kicking, biting, hitting, trying to wound with an object (gun, knife, piece of wood, pair of scissors, other object) or hot water. Sexual victimisation included unwanted touching, forced undressing and forced sexual activity. Consistent with previous work [7, 36], psychological victimisation was defined present if it occurred on two or more occasions, and violent/sexual victimisation on one or more occasions.

At both follow-up measurements, participants were asked about violent, psychological and sexual victimisation since the last assessment by any person in general, and if so, by whom (i.e. partner, ex-partner, family member, acquaintance, stranger). To reach consistency with the baseline questions, physical victimisation and psychological victimisation at follow-up were defined present if the respective form of victimisation was perpetrated by an intimate partner. Sexual victimisation at follow-up was defined present if it was perpetrated by any person in general, conform baseline measurement. The frequencies for all victimisation outcomes were similar to the frequencies at baseline.

Incident physical victimisation by a partner (hereafter: physical victimisation), incident psychological victimisation by a partner (hereafter: psychological victimisation) and incident sexual victimisation (hereafter: sexual victimisation) were defined as present if the participant reported the respective type of victimisation at any of the follow-up interviews, while participants with the respective type of victimisation at baseline were excluded. In addition, a summary variable (any incident adult victimisation) was generated to identify participants who experienced any form of adult victimisation at follow-up, but had no victimisation at baseline. Participants without a partner at baseline and any of the follow-up measurements were excluded when analysing physical victimisation, psychological victimisation or the summary variable.

\section{Confounders}

Age, gender, low socio-economic status, past criminal activity and substance use disorders were hypothesized to be confounders in the present analyses [13, 37]. Arrest was used as a measure of criminal activity. Self-reported arrest was obtained at baseline by asking participants if they had ever been arrested. In addition, CIDI 3.0 was used to define baseline, lifetime diagnoses of any substance use disorder. Finally, household income was a proxy for socio-economic status. The variable included three strata, based on monthly income: low $(<€ 1500)$, middle $(€ 1500-€ 3300)$ and high (>€3300).

\section{Statistical analyses}

All statistical analyses were performed using Stata version 13 [38]. Baseline characteristics were assessed for the complete sample. In addition, subjects with clinically validated PE at baseline were compared with subjects without clinically validated PE, using Chi-square tests and independent sample $t$ tests. 
Logistic regression analyses were performed to answer the six research questions. All regression models included age, gender, household income (dummies of strata), baseline substance use disorders and arrest as covariates. The numbers of the analyses correspond with the numbers in Fig. 1.

1. Logistic regression analyses were performed to examine the association between baseline PE and incident adult victimisation at follow-up in the complete sample.

2. The association between baseline childhood victimisation and incident adult victimisation was assessed in a separate logistic regression analysis.

3. To assess whether childhood victimisation moderated the association between PE and adult victimisation, a logistic regression analysis was performed using incident adult victimisation as the dependent variable and $\mathrm{PE}$, childhood victimisation and the interaction term $\mathrm{PE} *$ childhood victimisation as the independent variables. To any interaction effect, a logistic regression analysis was performed using incident adult victimisation as the dependent variable and a categorical variable containing the following categories as the independent variable, modelled as dummies: (1) No $\mathrm{PE}$, no childhood victimisation (reference group); (2) No PE, childhood victimisation present; (3) PE present, no childhood victimisation; (4) PE present, childhood victimisation present. If the interaction term was below alpha $(\alpha=0.10)$, the associations between $\mathrm{PE}$, childhood victimisation and adult victimisation were analysed stratified by presence or absence of PE and childhood victimisation, respectively.

4. The association between baseline adult victimisation and incident PE at follow-up was examined in a logistic regression analysis in the complete sample.

5. The association between childhood victimisation and incident $\mathrm{PE}$ was assessed in a logistic regression analysis in the complete sample.

6. The hypothesized moderating effect of childhood victimisation on the association between baseline adult victimisation and incident $\mathrm{PE}$ was examined by conducting a logistic regression analysis using incident $\mathrm{PE}$ as the dependent variable and adult victimisation, childhood victimisation and the interaction term adult victimisation * childhood victimisation as the independent variables. A logistic regression analysis was performed using incident $\mathrm{PE}$ as the dependent variable and a categorical variable containing the following categories as the independent variable: (1) No childhood victimisation, no adult victimisation (reference category); (2) childhood victimisation present, no adult victimisation; (3) no childhood victimisation, adult victimisation present; (4) childhood victimisation present, adult victimisation present. Again, if the $p$ value of the interaction term was below alpha $(\alpha=0.10)$, the associations between childhood victimisation, adult victimisation and $\mathrm{PE}$ were examined in stratified analyses.

\section{Results}

\section{Baseline characteristics}

At baseline, the complete sample included 6359 participants, after exclusion of individuals with self-reported PE who could not be reached for re-interview $(n=287)$. Of these participants, $5.3 \%(n=340)$ reported clinically validated PE. More women than men reported PE (Table 1). Moreover, the proportion of individuals with PE differed significantly between the strata of household income. Subjects with PE were overrepresented in the low income group and underrepresented in the high-income group. Furthermore, the baseline prevalence of childhood victimisation, adult victimisation, lifetime substance use disorders and arrest was significantly higher in individuals with PE (Table 1).

\section{The association between baseline psychotic experiences and adult victimisation}

The odds ratio (OR) of the association between baseline PE and any incident adult victimisation was 2.09 (95\% CI 0.79-5.56; Table 2). PE were associated with all forms of victimisation, but the OR was only statistically significant for the association between $\mathrm{PE}$ and sexual victimisation $(\mathrm{OR}=3.51,95 \%$ CI 1.54-7.96).

\section{The association between baseline childhood victimisation and adult victimisation}

Childhood victimisation was associated with all forms of adult victimisation, with ORs ranging from $2.70(95 \% \mathrm{CI}$ 1.41-5.16) for sexual victimisation to 5.49 (95\% CI 2.26-13.34) for physical victimisation (Table 2).

\section{The interaction between psychotic experiences and childhood victimisation on the outcome adult victimisation}

The interaction term $\mathrm{PE} *$ Childhood victimisation was below alpha for the outcome any adult victimisation (Table $2 ; p=0.08$ ). Follow-up analysis of the interaction between childhood victimisation and $\mathrm{PE}$ on the outcome 
Table 1 Baseline characteristics of individuals with and without clinically validated PE

\begin{tabular}{|c|c|c|c|c|c|c|c|}
\hline & $\begin{array}{l}\text { Complete } \\
\text { sample }\end{array}$ & $\begin{array}{l}\text { Subjects with } \\
\mathrm{PE}^{\mathrm{a}}\end{array}$ & $\begin{array}{l}\text { Subjects without } \\
\mathrm{PE}^{\mathrm{a}}\end{array}$ & $t$ & $\chi^{2}$ & $d f$ & $p^{\mathrm{b}}$ \\
\hline \multicolumn{8}{|l|}{ Demographics } \\
\hline$N$ & 6359 & 340 & 6019 & - & - & - & - \\
\hline Number of males $(\%)$ & $2852(44.9)$ & $127(37.4)$ & $2725(45.3)$ & - & 8.162 & 1 & 0.004 \\
\hline Age (SD) & $44.4(12.5)$ & $43.0(13.2)$ & $44.4(12.5)$ & 2.049 & - & 6357 & 0.041 \\
\hline Household income & - & - & - & - & 32.915 & 2 & $<0.001$ \\
\hline Low & $1439(25.4)$ & $119(38.4)$ & $1320(24.7)$ & - & - & - & - \\
\hline Middle & $2635(46.5)$ & $133(42.9)$ & $2502(46.7)$ & - & - & - & - \\
\hline High & $1590(28.1)$ & $58(18.7)$ & $1532(28.6)$ & - & - & - & - \\
\hline \multicolumn{8}{|l|}{ Baseline victimisation } \\
\hline Childhood victimisation, $N(\%)$ & $2138(34.4)$ & $207(61.8)$ & $1931(32.8)$ & - & 118.161 & 1 & $<0.001$ \\
\hline Physical victimisation by partner, $N(\%)$ & $614(10.3)$ & $73(23.3)$ & $541(9.6)$ & - & 60.216 & 1 & $<0.001$ \\
\hline $\begin{array}{l}\text { Psychological victimisation by partner, } \\
N(\%)\end{array}$ & $1716(28.9)$ & $148(47.4)$ & $1568(27.9)$ & - & 55.106 & 1 & $<0.001$ \\
\hline Sexual violence victimisation, $N(\%)$ & $279(4.5)$ & $47(14.1)$ & $232(4.0)$ & - & 75.956 & 1 & $<0.001$ \\
\hline Any adult victimisation, $N(\%)$ & $1940(33.2)$ & $171(55.0)$ & $1769(32.0)$ & - & 70.355 & 1 & $<0.001$ \\
\hline \multicolumn{8}{|l|}{ Baseline confounders } \\
\hline Any lifetime substance use disorder & $1037(16.3)$ & $106(31.2)$ & $931(15.5)$ & - & 58.187 & 1 & $<0.001$ \\
\hline Ever arrested & $1346(21.2)$ & $88(26.0)$ & $1258(20.9)$ & - & 4.906 & 1 & 0.027 \\
\hline
\end{tabular}

a Clinically validated PE

${ }^{\mathrm{b}} p$-value resulting from $t$ test or Chi-square test for difference between participants with vs. without PE

adult victimisation, using a categorical predictor, showed that isolated PE $(\mathrm{OR}=4.49,95 \%$ CI $1.27-15.90)$ and isolated childhood victimisation $(\mathrm{OR}=3.73,95 \%$ CI 2.16-6.47) were associated with an increased risk of any adult victimisation. However, the co-occurrence of PE and childhood victimisation was associated with a lower risk of any adult victimisation than their isolated effects $(\mathrm{OR}=2.88,95 \%$ CI $0.62-13.39)$, thus indicating a negative interaction. Analyses in the subsample stratified by presence or absence of childhood victimisation showed that PE were associated with adult victimisation in the subsample without childhood victimisation $(\mathrm{OR}=4.81,95 \%$ CI 1.34-17.29). However, in the subsample with childhood victimisation there was no association between $\mathrm{PE}$ and adult victimisation. Similarly, childhood victimisation was associated with adult victimisation in the subsample without baseline PE (OR $=3.76,95 \%$ CI 2.17-6.53), but was not associated with adult victimisation in the subsample with baseline PE. Results for the outcomes physical victimisation and psychological victimisation were similar to the results of any adult victimisation and showed a trend towards a negative interaction as well $(p=0.16$ for physical victimisation, $p=0.07$ for psychological victimisation). Interaction could not be examined in the model with sexual victimisation as the outcome, because none of the subjects had PE in absence of childhood victimisation. However, the co-occurrence of PE and childhood victimisation ( $\mathrm{OR}=8.72,95 \%$ CI 3.40-22.32) showed a stronger association with sexual victimisation than isolated childhood victimisation $(\mathrm{OR}=2.24,95 \%$ CI $1.10-4.57)$.

The association between baseline adult victimisation and incident psychotic experiences

In the complete sample, all forms of baseline adult victimisation were associated with incident PE, with ORs ranging from 1.88 (95\% CI 1.34-2.64) for psychological victimisation to 3.77 (95\% CI 2.32-6.12) for sexual victimisation, after adjustment for confounders (Table 3).

\section{The association between baseline childhood victimisation and incident psychotic experiences}

Childhood victimisation was associated with incident $\mathrm{PE}$ in the complete sample (Table 3; OR $=2.64,95 \%$ CI 1.90-3.66).

\section{The interaction between childhood victimisation and adult victimisation on the outcome psychotic experiences}

The risk of PE in subjects with both childhood victimisation and adult victimisation was not larger than the product of their risks in participants with isolated adult 


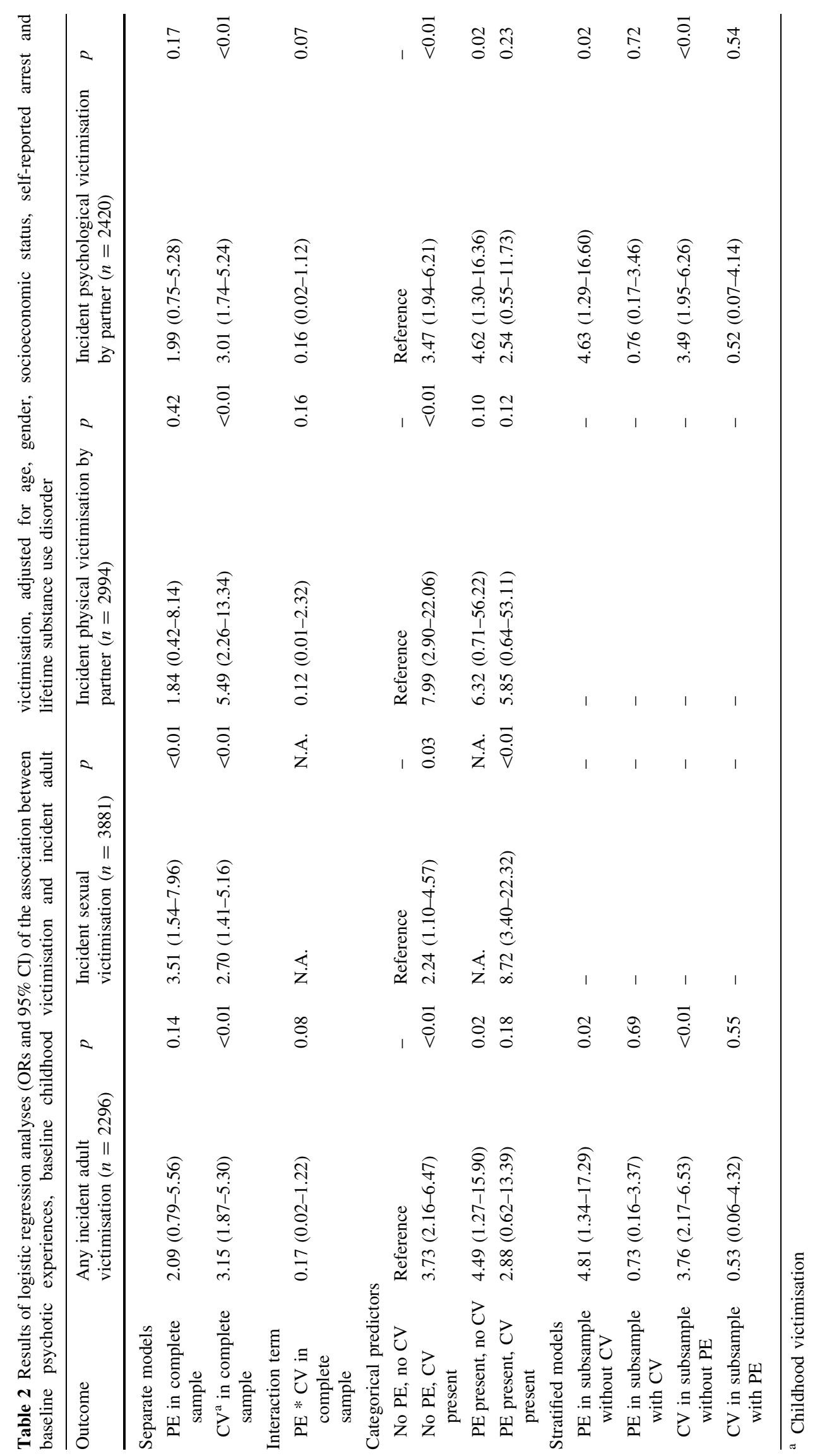


victimisation and subjects with isolated childhood victimisation separately, indicating that there was no interaction between adult victimisation and childhood victimisation (Table 3).

\section{Discussion}

\section{Overview of results}

To our knowledge, the present study is the first to examine the bidirectional, longitudinal associations between PE and adult victimisation using a prospective, general population sample, while also assessing the moderating effect of childhood victimisation. It was hypothesized that $\mathrm{PE}$ increase the risk of incident adult victimisation, and that adult victimisation increases the risk of incident PE. Moreover, it was hypothesized that childhood victimisation increases the risk of both adult victimisation and PE and that the bidirectional associations between $\mathrm{PE}$ and adult victimisation would be increased by the presence of childhood victimisation (Fig. 1). The present results showed evidence for the hypothesized bidirectional association between adult victimisation and PE. However, the hypothesis of a positive interaction between childhood victimisation and both $\mathrm{PE}$ and adult victimisation was falsified (Fig. 2).

\section{The association between baseline psychotic experiences and incident adult victimisation}

Previous studies reported an association between psychotic disorder and adult victimisation [8, 15, 37, 39]. However, the temporal sequence of the association could not be determined in these studies because all studies used crosssectional study designs. The present study showed that individuals with isolated PE or isolated childhood victimisation at baseline were at increased risk of any adult victimisation. However, contrary to our hypothesis that PE and childhood victimisation would act synergistically to increase the risk of adult victimisation, results showed that the co-occurrence of PE with childhood victimisation was associated with a lower risk of adult victimisation than isolated PE or isolated childhood victimisation. The results of the stratified analyses revealed that exposure to PE after childhood victimisation was not associated with adult victimisation, while $\mathrm{PE}$ increased the risk of adult victimisation in individuals without childhood victimisation. Similarly, exposure to childhood victimisation was not a risk factor for adult victimisation in adults exposed to PE, while childhood victimisation did increase the risk of adult victimisation in individuals not exposed to $\mathrm{PE}$. Therefore, there was a negative interaction effect, pointing towards

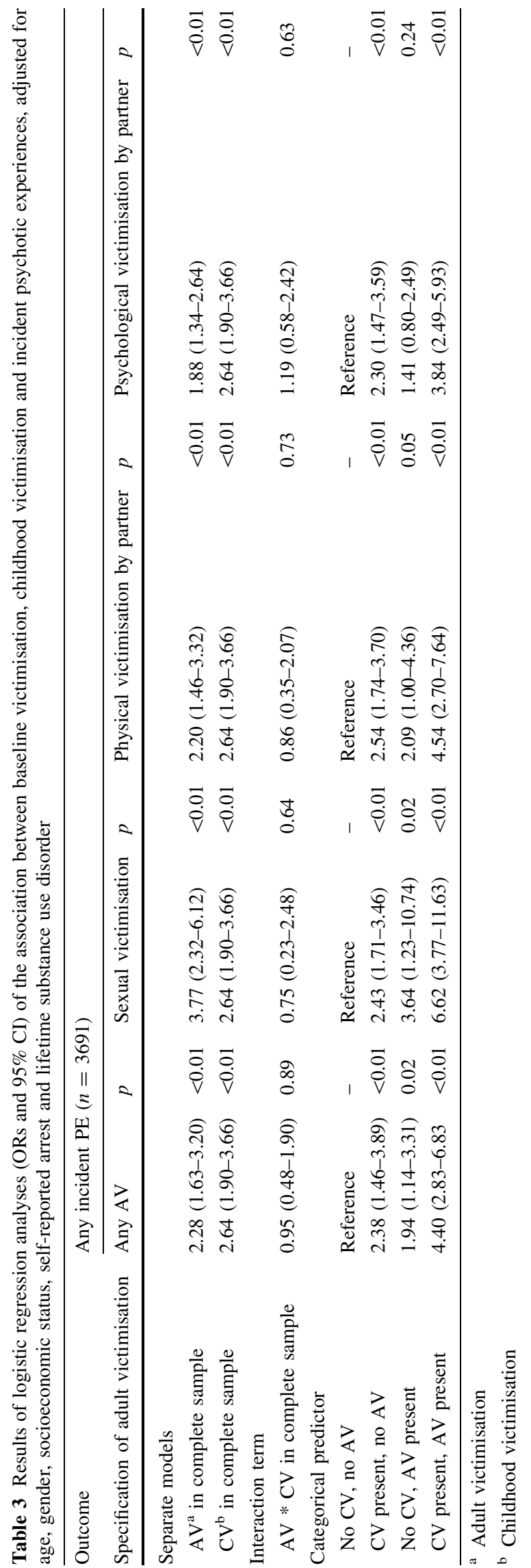




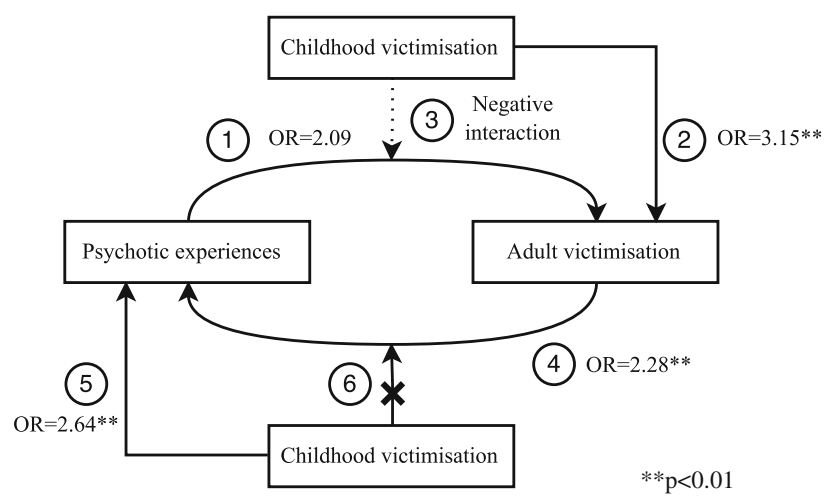

Fig. 2 Results of testing the hypotheses relating to the bidirectional association between psychotic experiences and victimisation

'parallelism' instead of the hypothesized 'synergism' [40, 41], thus suggesting that PE and childhood victimisation act through competing pathways in increasing risk for adult victimisation. In other words, any excess risk for adult victimisation would already have been consumed after isolated exposure to either PE or childhood victimisation.

The results for the outcomes physical victimisation and psychological victimisation were similar to the results of the outcome of any adult victimisation, showing a trend towards a negative interaction. However, interaction could not be examined for the outcome of sexual victimisation. As opposed to the results for physical victimisation and psychological victimisation, available results show that $\mathrm{PE}$ were associated with incident sexual victimisation in the subgroup with childhood victimisation. However, the interaction could not be analysed. Therefore, it is possible that the association between PE and adult sexual victimisation differs from the associations between PE and other forms of adult victimisation. This finding would be in line with previous research that found that childhood sexual abuse was differentially associated with psychosis compared to other victimising experiences during childhood $[9,12,29]$.

The mechanisms behind the association between PE and incident adult victimisation remain unclear. One possible explanation is that individuals with PE display disordered behaviour, for example arising from paranoid delusions, leading to social conflict and victimisation. Previous research showed that PE increase the risk of violence perpetration [36]. Therefore, it is possible that adult victimisation occurs in response to violence perpetration. Another possible explanation is that individuals with $\mathrm{PE}$ live in poorer social environments where adult victimisation is more likely to occur. However, the present analyses were adjusted for household income as a proxy for socioeconomic status. Finally, it is possible that individuals with $\mathrm{PE}$ are more likely to report adult victimisation, for example because of paranoid interpretations of social interactions. To our knowledge, the reliability of adult victimisation reports in individuals with psychosis has not been studied. However, it has been shown that individuals with psychosis are able to provide reliable reports of childhood victimisation [42, 43]. Therefore, it is unlikely that the association between $\mathrm{PE}$ and adult victimisation can be fully attributed to differential reporting of adult victimisation by individuals with PE.

\section{The association between baseline adult victimisation and incident psychotic experiences}

Results of the present study showed that all forms of adult victimisation were associated with the development of incident PE. This confirms our hypothesis that the association between PE and adult victimisation is bidirectional, similar to the previously reported bidirectional association between PE and childhood victimisation [10]. Consistent with previous work [10-12, 16, 44], childhood victimisation was associated with incident PE, both in the presence and absence of co-occurring adult victimisation. However, to our hypothesis of a positive interaction between childhood victimisation and adult victimisation for the outcome of incident PE, the risk of PE in subjects with both childhood victimisation and adult victimisation was not larger than the product of the isolated risks. This finding is not fully consistent with the previous literature, which showed positive interactions between childhood victimisation and adult victimisation for the outcome PE [21, 30, 32]. However, all studies used a wide variety of definitions of childhood victimisation and adult victimisation, thus impeding direct comparison. The present results show that childhood victimisation and adult victimisation are independent, cumulative risk factors for PE. This finding is relevant, since poly-victimisation is prevalent among individuals with severe mental illness $[9,15]$. Moreover, this finding shows that there are two pathways from childhood victimisation to psychosis: one direct one and one indirect one through adult victimisation.

Literature on the mechanisms behind the association between adult victimisation and incident psychosis is scarce. However, both adult victimisation and childhood victimisation have been linked to various non-psychotic mental disorders [45-49]. Since PE are prevalent among individuals with non-psychotic mental disorders $[18,50]$ and have been identified as an indicator of severity in nonpsychotic psychopathology [50-54], the link between adult victimisation and incident $\mathrm{PE}$ is possibly confounded by the presence of non-psychotic psychopathology [50-54]. Furthermore, it is likely that the mechanisms underlying the impact of adult victimisation on psychosis are similar to the mechanisms mediating impact of childhood 
victimisation on psychosis $[21,55]$. Various biological and psychological processes have been associated with both psychosis and childhood victimisation [11, 56, 57]. Biological processes that link victimisation with an increase in psychosis risk include hyperactivation and sensitization of the hypothalamic-pituitary-adrenal (HPA) axis, decreased hippocampal volume, reduced brain-derived neurotrophic factor (BDNF) [56] and increased dopamine release [11]. Furthermore, victimisation may increase the risk of psychosis psychologically by contributing to the development of a worrying thinking style, negative beliefs about the self and reasoning biases such as jumping to conclusions [57]. However, more research to examine the mechanisms underlying the link between psychosis and adult victimisation is needed.

\section{Strengths and limitations}

Strength of the present study is the prospective, longitudinal study design that enables the bidirectional assessment of psychosis and victimisation in a general population sample, while controlling for various confounders identified in the literature. Another strength is the use of clinically validated PE instead of self-reported PE [58].

The results of the study should be interpreted in the light of some limitations. First, the definitions of incident physical and psychological victimisation had to be restricted to victimisation by an intimate partner to remain consistent with the baseline definitions in the dataset. To overcome this limitation, individuals without a partner at baseline and any of the follow-up measurements were excluded from the analyses when using physical victimisation, psychological victimisation or any adult victimisation as the outcome, resulting in an exclusion of 1066 individuals for the present analysis. To our knowledge, no previous study examined whether victimisation by an intimate partner may be differently associated with psychosis than victimisation by any person. To examine this, sensitivity analyses were conducted examining the association between baseline PE and adult victimisation by any person at follow-up, while excluding individuals without a partner at baseline. The results of these sensitivity analyses were similar to the results of the main analyses in terms of effect size. However, statistical significance was greater as a result of increased statistical power. Therefore, the association between $\mathrm{PE}$ and adult victimisation perpetrated by any person appears to be similar to the association between $\mathrm{PE}$ and adult victimisation perpetrated by an intimate partner. However, more research is required to investigate this issue.

Second, baseline data on household income was missing for 604 individuals. Again, sensitivity analyses were conducted using the missing data as a separate category. Results of these analyses were similar to the main results.

Third, statistical power was low in some analyses, in particular in the interaction analyses. Thus, to screen for potential interactions, alpha for interaction effects was set at 0.10 . Raising the alpha to 0.10 increases the risk of false positive results. Therefore, it is possible that some results represent type I error. More studies are required to replicate the interactions identified in this study.

Furthermore, data about baseline victimisation was collected retrospectively. Since participants in this study were aged 18-64 years, it is possible that differences in recall impacted the results. Previous studies showed evidence for age-related differential recall, with individuals underreporting victimisation as age increases [59-61]. Therefore, it is possible that the associations between victimisation and psychosis identified in this study would be stronger in the absence of age-related differential recall. In addition, the risk of exposure to adult victimisation and $\mathrm{PE}$ varies by age, suggesting an interaction effect between age, PE and adult victimisation. To examine this, sensitivity analyses were conducted testing for interaction effects between the various predictor variables and five age categories. Results of this analysis showed that there was no evidence for interaction between any of the predictor variables and age when studying incident PE. In addition, the association between baseline PE and incident AV did not differ between the various age groups above 25 years, but there was some evidence for a decreased association in the youngest age group (18-25 years). However, statistical power in the youngest age group was insufficient to further explore this finding. Other studies with more young adults are needed to study this hypothesis.

Finally, follow-up data was missing for 2028 participants (attrition $=30.5 \%$ ). Attrition was associated with sociodemographic factors, but not with mental health status, making it unlikely that attrition would induce bias [62]. In addition, attrition was not associated with baseline PE or baseline victimisation status. Therefore, selective attrition is unlikely to have biased the results.

\section{Conclusions and implications}

The present study did not find evidence for all hypotheses (Fig. 2). To integrate this updated evidence, Fig. 2 was transformed into Fig. 3, removing the connections that were not supported by the present results. PE and childhood victimisation were identified as competing risk factors for adult victimisation. In addition, childhood victimisation and adult victimisation were independent, cumulative risk factors for PE. Thus, PE and adult victimisation are bidirectionally associated in individuals 


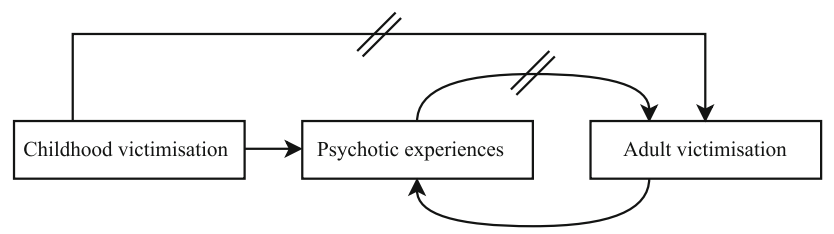

Fig. 3 The complex interplay of psychosis and victimisation across the life course. // Points towards parallelism, i.e. childhood victimisation and psychotic experiences are competing risk factors for adult victimisation

without childhood victimisation. In individuals with childhood victimisation, there are two pathways from childhood victimisation to PE: one direct and one indirect through adult victimisation. In conclusion, psychosis and victimisation are strongly interconnected throughout the life course, resulting in a complex interplay in which childhood victimisation and adult victimisation lead to both $\mathrm{PE}$ and re-victimising experiences. Because victimisation across the life course has been associated with several adverse consequences [49, 63-66], prevention strategies against victimisation, both during childhood and during adulthood, are important to prevent individuals from entering a spiral leading to mental illness and re-victimisation. Moreover, intervention programs are needed to prevent further re-victimisation in individuals who have already experienced victimisation. However, the development of adequate prevention and intervention programs requires further understanding of the mechanisms underlying the associations identified in the present study. Therefore, more longitudinal research is required to obtain a deeper understanding of the complex interplay between psychosis and victimisation across the life course.

Acknowledgements NEMESIS-2 is conducted by the Netherlands Institute of Mental Health and Addiction (Trimbos Institute) in Utrecht. Financial support has been received from the Ministry of Health, Welfare and Sport, with supplementary support from the Netherlands Organization for Health Research and Development (ZonMw) and the Genetic Risk and Outcome of Psychosis (GROUP) investigators. Funding was provided by Ministerie van Volksgezondheid, Welzijn en Sport (Grant No. 310253).

\section{Compliance with ethical standards}

Ethical standards NEMESIS-2 was approved by the Medical Ethics Review Committee for Institutions on Mental Health Care (METIGG). Participants provided written informed consent to participate in the interview, after full written and verbal information about the study was given before and at the start of the baseline assessment.

Conflict of interest On behalf of all authors, the corresponding author states that there is no conflict of interest.

Open Access This article is distributed under the terms of the Creative Commons Attribution 4.0 International License (http://crea tivecommons.org/licenses/by/4.0/), which permits unrestricted use, distribution, and reproduction in any medium, provided you give appropriate credit to the original author(s) and the source, provide a link to the Creative Commons license, and indicate if changes were made.

\section{References}

1. Coid JW, Ullrich S, Bebbington P, Fazel S, Keers R (2016) Paranoid ideation and violence: meta-analysis of individual subject data of 7 population surveys. Schizophr Bull 42(4):907-915. doi:10.1093/schbul/sbw006

2. Douglas KS, Guy LS, Hart SD (2009) Psychosis as a risk factor for violence to others: a meta-analysis. Psychol Bull 135(5):679-706. doi:10.1037/a0016311

3. Fazel S, Gulati G, Linsell L, Geddes JR, Grann M (2009) Schizophrenia and violence: systematic review and meta-analysis. PLoS Med 6(8):e1000120. doi:10.1371/journal.pmed. 1000120

4. Fazel S, Yu R (2011) Psychotic disorders and repeat offending: systematic review and meta-analysis. Schizophr Bull 37(4):800-810. doi:10.1093/schbul/sbp135

5. Large MM, Nielssen O (2011) Violence in first-episode psychosis: a systematic review and meta-analysis. Schizophr Res 125(2-3):209-220. doi:10.1016/j.schres.2010.11.026

6. Crisp AH, Gelder MG, Rix S, Meltzer HI, Rowlands OJ (2000) Stigmatisation of people with mental illnesses. Br J Psychiatry 177:4-7

7. Ten Have M, de Graaf R, van Weeghel J, van Dorsselaer S (2014) The association between common mental disorders and violence: to what extent is it influenced by prior victimization, negative life events and low levels of social support? Psychol Med 44(7):1485-1498. doi:10.1017/S0033291713002262

8. Choe JY, Teplin LA, Abram KM (2008) Perpetration of violence, violent victimization, and severe mental illness: balancing public health concerns. Psychiatr Serv 59(2):153-164. doi:10.1176/ps. 2008.59.2.153

9. Bebbington PE, Bhugra D, Brugha T, Singleton N, Farrell M, Jenkins R, Lewis G, Meltzer H (2004) Psychosis, victimisation and childhood disadvantage: evidence from the second British National Survey of Psychiatric Morbidity. Br J Psychiatry 185(3):220-226. doi:10.1192/bjp.185.3.220

10. Kelleher I, Keeley H, Corcoran P, Ramsay H, Wasserman C, Carli V, Sarchiapone M, Hoven C, Wasserman D, Cannon M (2013) Childhood trauma and psychosis in a prospective cohort study: cause, effect, and directionality. Am J Psychiatry 170(7):734-741. doi:10.1176/appi.ajp.2012.12091169

11. Morgan C, Gayer-Anderson C (2016) Childhood adversities and psychosis: evidence, challenges, implications. World Psychiatry 15(2):93-102. doi:10.1002/wps. 20330

12. Read J, van Os J, Morrison AP, Ross CA (2005) Childhood trauma, psychosis and schizophrenia: a literature review with theoretical and clinical implications. Acta Psychiatr Scand 112(5):330-350. doi:10.1111/j.1600-0447.2005.00634.x

13. de Mooij LD, Kikkert M, Lommerse NM, Peen J, Meijwaard SC, Theunissen J, Duurkoop PW, Goudriaan AE, Van HL, Beekman AT, Dekker JJ (2015) Victimisation in adults with severe mental illness: prevalence and risk factors. $\mathrm{Br} \mathrm{J}$ Psychiatry 207(6):515-522. doi:10.1192/bjp.bp.113.143370

14. Hart C, de Vet R, Moran P, Hatch SL, Dean K (2012) A UK population-based study of the relationship between mental disorder and victimisation. Soc Psychiatry Psychiatr Epidemiol 47(10):1581-1590. doi:10.1007/s00127-011-0464-7

15. Kamperman AM, Henrichs J, Bogaerts S, Lesaffre EM, Wierdsma AI, Ghauharali RR, Swildens W, Nijssen Y, van der 
Gaag M, Theunissen JR, Delespaul PA, van Weeghel J, van Busschbach JT, Kroon H, Teplin LA, van de Mheen D, Mulder CL (2014) Criminal victimisation in people with severe mental illness: a multi-site prevalence and incidence survey in the Netherlands. PLoS ONE 9(3):e91029. doi:10.1371/journal.pone. 0091029

16. Varese F, Smeets F, Drukker M, Lieverse R, Lataster $T$, Viechtbauer W, Read J, van Os J, Bentall RP (2012) Childhood adversities increase the risk of psychosis: a meta-analysis of patient-control, prospective- and cross-sectional cohort studies. Schizophr Bull 38(4):661-671. doi:10.1093/schbul/sbs050

17. Wolke D, Lereya ST, Fisher HL, Lewis G, Zammit S (2014) Bullying in elementary school and psychotic experiences at 18 years: a longitudinal, population-based cohort study. Psychol Med 44(10):2199-2211. doi:10.1017/S0033291713002912

18. Van Os J, Hanssen M, Bijl R, Ravelli A (2000) Straus (1969) revisited: a psychosis continuum in the general population? Schizophr Res 45(1-2):11-20

19. van Os J, Linscott RJ (2012) Introduction: the extended psychosis phenotype-relationship with schizophrenia and with ultrahigh risk status for psychosis. Schizophr Bull 38(2):227-230. doi:10. 1093/schbul/sbr188

20. van Os J, Reininghaus U (2016) Psychosis as a transdiagnostic and extended phenotype in the general population. World Psychiatry 15(2):118-124. doi:10.1002/wps.20310

21. Lataster J, Myin-Germeys I, Lieb R, Wittchen HU, van Os J (2012) Adversity and psychosis: a 10-year prospective study investigating synergism between early and recent adversity in psychosis. Acta Psychiatr Scand 125(5):388-399. doi:10.1111/j. 1600-0447.2011.01805.x

22. Khalifeh H, Oram S, Osborn D, Howard LM, Johnson S (2016) Recent physical and sexual violence against adults with severe mental illness: a systematic review and metaanalysis. Int Rev Psychiatry 28(5):433-451. doi:10.1080/ 09540261.2016.1223608

23. Widom CS, Czaja SJ, Dutton MA (2008) Childhood victimization and lifetime revictimization. Child Abuse Negl 32(8):785-796. doi:10.1016/j.chiabu.2007.12.006

24. Barrios YV, Gelaye B, Zhong Q, Nicolaidis C, Rondon MB, Garcia PJ, Sanchez PA, Sanchez SE, Williams MA (2015) Association of childhood physical and sexual abuse with intimate partner violence, poor general health and depressive symptoms among pregnant women. PLoS ONE 10(1):e0116609. doi:10. 1371/journal.pone.0116609

25. Bensley L, Van Eenwyk J, Wynkoop Simmons K (2003) Childhood family violence history and women's risk for intimate partner violence and poor health. Am J Prev Med 25(1):38-44

26. Blom H, Hogberg U, Olofsson N, Danielsson I (2014) Strong association between earlier abuse and revictimization in youth. BMC Publ Health 14:715. doi:10.1186/1471-2458-14-715

27. Coid J, Petruckevitch A, Feder G, Chung W, Richardson J, Moorey S (2001) Relation between childhood sexual and physical abuse and risk of revictimisation in women: a cross-sectional survey. Lancet 358(9280):450-454

28. McIntyre JK, Widom CS (2011) Childhood victimization and crime victimization. J Interpers Violence 26(4):640-663. doi:10. 1177/0886260510365868

29. Fry D, McCoy A, Swales D (2012) The consequences of maltreatment on children's lives: a systematic review of data from the East Asia and Pacific Region. Trauma Violence Abuse 13(4):209-233. doi:10.1177/1524838012455873

30. Bebbington P, Jonas S, Kuipers E, King M, Cooper C, Brugha T, Meltzer H, McManus S, Jenkins R (2011) Childhood sexual abuse and psychosis: data from a cross-sectional national psychiatric survey in England. Br J Psychiatry 199(1):29-37. doi:10. 1192/bjp.bp.110.083642
31. Morgan C, Reininghaus U, Fearon P, Hutchinson G, Morgan K, Dazzan P, Boydell J, Kirkbride JB, Doody GA, Jones PB, Murray RM, Craig T (2014) Modelling the interplay between childhood and adult adversity in pathways to psychosis: initial evidence from the AESOP study. Psychol Med 44(2):407-419. doi:10. 1017/S0033291713000767

32. Morgan C, Reininghaus U, Reichenberg A, Frissa S, Hotopf M, Hatch SL, Team SEs (2014) Adversity, cannabis use and psychotic experiences: evidence of cumulative and synergistic effects. Br J Psychiatry 204:346-353. doi:10.1192/bjp.bp.113. 134452

33. de Graaf R, Ten Have M, van Dorsselaer S (2010) The Netherlands Mental Health Survey and Incidence Study-2 (NEMESIS2): design and methods. Int $J$ Methods Psychiatr Res 19(3):125-141. doi:10.1002/mpr.317

34. Haro JM, Arbabzadeh-Bouchez S, Brugha TS, de Girolamo G, Guyer ME, Jin R, Lepine JP, Mazzi F, Reneses B, Vilagut G, Sampson NA, Kessler RC (2006) Concordance of the Composite International Diagnostic Interview Version 3.0 (CIDI 3.0) with standardized clinical assessments in the WHO World Mental Health surveys. Int J Methods Psychiatr Res 15(4):167-180

35. van Nierop M, van Os J, Gunther N, Myin-Germeys I, de Graaf R, ten Have M, van Dorsselaer S, Bak M, van Winkel R (2012) Phenotypically continuous with clinical psychosis, discontinuous in need for care: evidence for an extended psychosis phenotype. Schizophr Bull 38(2):231-238. doi:10.1093/schbul/sbr129

36. Honings S, Drukker M, Ten Have M, de Graaf R, van Dorsselaer S, van Os J (2016) Psychotic experiences and risk of violence perpetration and arrest in the general population: a prospective study. PLoS ONE 11(7):e0159023. doi:10.1371/journal.pone. 0159023

37. Morgan VA, Morgan F, Galletly C, Valuri G, Shah S, Jablensky A (2016) Sociodemographic, clinical and childhood correlates of adult violent victimisation in a large, national survey sample of people with psychotic disorders. Soc Psychiatry Psychiatr Epidemiol 51(2):269-279. doi:10.1007/s00127-015-1155-6

38. StataCorp. (2013) Stata Statistical Software: Release 13. StataCorp LP, College Station

39. Latalova K, Kamaradova D, Prasko J (2014) Violent victimization of adult patients with severe mental illness: a systematic review. Neuropsychiatr Dis Treat 10:1925-1939. doi:10.2147/ NDT.S68321

40. Darroch J (1997) Biologic synergism and parallelism. Am J Epidemiol 145(7):661-668

41. Murray RM, Jones PB, Susser E, Van Os J, Cannon M (2002) The Epidemiology of Schizophrenia. Cambridge University Press

42. Goodman LA, Thompson KM, Weinfurt K, Corl S, Acker P, Mueser KT, Rosenberg SD (1999) Reliability of reports of violent victimization and posttraumatic stress disorder among men and women with serious mental illness. J Trauma Stress 12(4):587-599. doi:10.1023/A:1024708916143

43. Fisher HL, Craig TK, Fearon P, Morgan K, Dazzan P, Lappin J, Hutchinson G, Doody GA, Jones PB, McGuffin P, Murray RM, Leff J, Morgan C (2011) Reliability and comparability of psychosis patients' retrospective reports of childhood abuse. Schizophr Bull 37(3):546-553. doi:10.1093/schbul/sbp103

44. Lataster T, van Os J, Drukker M, Henquet C, Feron F, Gunther N, Myin-Germeys I (2006) Childhood victimisation and developmental expression of non-clinical delusional ideation and hallucinatory experiences: victimisation and non-clinical psychotic experiences. Soc Psychiatry Psychiatr Epidemiol 41(6):423-428. doi:10.1007/s00127-006-0060-4

45. Lagdon S, Armour C, Stringer M (2014) Adult experience of mental health outcomes as a result of intimate partner violence victimisation: a systematic review. Eur J Psychotraumatol. doi:10.3402/ejpt.v5.24794 
46. Burnam MA, Stein JA, Golding JM, Siegel JM, Sorenson SB, Forsythe AB, Telles CA (1988) Sexual assault and mental disorders in a community population. J Consult Clin Psychol 56(6):843-850. doi:10.1037/0022-006X.56.6.843

47. Mueser KT, Rosenberg SD, Goodman LA, Trumbetta SL (2002) Trauma, PTSD, and the course of severe mental illness: an interactive model. Schizophr Res 53(1-2):123-143. doi:10.1016/ S0920-9964(01)00173-6

48. Logan T (2006) Women and victimization: contributing factors, interventions, and implications. American Psychological Association

49. Kessler RC, McLaughlin KA, Green JG, Gruber MJ, Sampson NA, Zaslavsky AM, Aguilar-Gaxiola S, Alhamzawi AO, Alonso J, Angermeyer M, Benjet C, Bromet E, Chatterji S, de Girolamo G, Demyttenaere K, Fayyad J, Florescu S, Gal G, Gureje O, Haro JM, Hu CY, Karam EG, Kawakami N, Lee S, Lepine JP, Ormel J, Posada-Villa J, Sagar R, Tsang A, Ustun TB, Vassilev S, Viana MC, Williams DR (2010) Childhood adversities and adult psychopathology in the WHO World Mental Health Surveys. Br J Psychiatry 197(5):378-385. doi:10.1192/bjp.bp.110.080499

50. Kelleher I, Keeley H, Corcoran P, Lynch F, Fitzpatrick C, Devlin N, Molloy C, Roddy S, Clarke MC, Harley M, Arseneault L, Wasserman C, Carli V, Sarchiapone M, Hoven C, Wasserman D, Cannon M (2012) Clinicopathological significance of psychotic experiences in non-psychotic young people: evidence from four population-based studies. Br J Psychiatry 201(1):26-32. doi:10. 1192/bjp.bp.111.101543

51. Wigman JT, van Nierop M, Vollebergh WA, Lieb R, BeesdoBaum K, Wittchen HU, van Os J (2012) Evidence that psychotic symptoms are prevalent in disorders of anxiety and depression, impacting on illness onset, risk, and severity-implications for diagnosis and ultra-high risk research. Schizophr Bull 38(2):247-257. doi:10.1093/schbul/sbr196

52. Wigman JT, van Os J, Abidi L, Huibers MJ, Roelofs J, Arntz A, Kelleher I, Peeters FP (2014) Subclinical psychotic experiences and bipolar spectrum features in depression: association with outcome of psychotherapy. Psychol Med 44(2):325-336. doi:10. 1017/S0033291713000871

53. Perlis RH, Uher R, Ostacher M, Goldberg JF, Trivedi MH, Rush AJ, Fava M (2011) Association between bipolar spectrum features and treatment outcomes in outpatients with major depressive disorder. Arch Gen Psychiatry 68(4):351-360. doi:10.1001/ archgenpsychiatry.2010.179

54. Guloksuz S, van Nierop M, Lieb R, van Winkel R, Wittchen HU, van Os J (2015) Evidence that the presence of psychosis in nonpsychotic disorder is environment-dependent and mediated by severity of non-psychotic psychopathology. Psychol Med 45(11):2389-2401. doi:10.1017/S0033291715000380

55. Galletly C, Van Hooff M, McFarlane A (2011) Psychotic symptoms in young adults exposed to childhood trauma-a
20 year follow-up study. Schizophr Res 127(1-3):76-82. doi:10. 1016/j.schres.2010.12.010

56. Ruby E, Polito S, McMahon K, Gorovitz M, Corcoran C, Malaspina D (2014) Pathways Associating Childhood Trauma to the Neurobiology of Schizophrenia. Front Psychol Behav Sci 3(1):1-17

57. Freeman D, Garety P (2014) Advances in understanding and treating persecutory delusions: a review. Soc Psychiatry Psychiatr Epidemiol 49(8):1179-1189. doi:10.1007/s00127-014-0928-7

58. Linscott RJ, van Os J (2013) An updated and conservative systematic review and meta-analysis of epidemiological evidence on psychotic experiences in children and adults: on the pathway from proneness to persistence to dimensional expression across mental disorders. Psychol Med 43(6):1133-1149. doi:10.1017/ S0033291712001626

59. Yoshihama M, Gillespie BW (2002) Age adjustment and recall bias in the analysis of domestic violence data: methodological improvements through the application of survival analysis methods. Journal of Family Violence 17(3):199-221. doi:10. 1023/a:1016001211182

60. Widom CS, Morris S (1997) Accuracy of adult recollections of childhood victimization, Part 2: childhood sexual abuse. Psychol Assess 9(1):34

61. Widom CS, Shepard RL (1996) Accuracy of adult recollections of childhood victimization: part 1. Childhood physical abuse. Psychol Assess 8(4):412-421. doi:10.1037/1040-3590.8.4.412

62. de Graaf R, van Dorsselaer S, Tuithof M, Ten Have M (2013) Sociodemographic and psychiatric predictors of attrition in a prospective psychiatric epidemiological study among the general population. Result of the Netherlands Mental Health Survey and Incidence Study-2. Compr Psychiatry 54(8):1131-1139. doi:10. 1016/j.comppsych.2013.05.012

63. Palm A, Danielsson I, Skalkidou A, Olofsson N, Hogberg U (2016) Violence victimisation-a watershed for young women's mental and physical health. Eur J Publ Health 26(5):861-867. doi:10.1093/eurpub/ckv234

64. Hodgins S, Lincoln T, Mak T (2009) Experiences of victimisation and depression are associated with community functioning among men with schizophrenia. Soc Psychiatry Psychiatr Epidemiol 44(6):448-457. doi:10.1007/s00127-008-0460-8

65. Lysaker PH, Meyer PS, Evans JD, Clements CA, Marks KA (2001) Childhood sexual trauma and psychosocial functioning in adults with schizophrenia. Psychiatr Serv 52(11):1485-1488. doi:10.1176/appi.ps.52.11.1485

66. Newman JM, Turnbull A, Berman BA, Rodrigues S, Serper MR (2010) Impact of traumatic and violent victimization experiences in individuals with schizophrenia and schizoaffective disorder. J Nerv Ment Dis 198(10):708-714. doi:10.1097/NMD. 0b013e3181f49bf1 